\title{
Predicting difficult orotracheal intubation in pharyngo-laryngeal disease: preliminary results of a composite index
}

\author{
[La prédiction de difficulté d'intubation orotrachéale en cas de lésion \\ pharyngo-laryngée : résultats préliminaires d'un indice composé]
}

M. Angeles Ayuso MD, Xavier Sala MD, Mercè Luis MD, Joan M. Carbó MD

Purpose: Prediction of difficulty in orotracheal intubation (DI) in patients undergoing laryngeal microsurgery should help reduce the morbidity-mortality associated with this clinical situation. To establish a simple score to predict this difficulty, we studied I I variables and their association with DI in these patients.

Methods: The study included 181 patients. The variables evaluated were: Mallampati grade, thyromental distance, mouth opening, temporomandibular joint movement, tooth morphology, maxillary deficiency, head and neck movement, receding mandible, body mass index, and clinical symptoms of laryngeal and supraglottic disease. To establish the score, regression coefficients of the statistically significant variables were used on adjusted logistic regression analysis.

Results: DI was present in 50 patients (28\%) and orotracheal intubation was impossible in four (2\%). Except for obesity, all the variables evaluated were predictive of DI. A simple predictive test was established based on logistic regression analysis including all the variables except temporomandibular joint movement. To determine the optimum cut-off for the new test, a receiver operating characteristic curve analysis was applied. A score $\geq 5$ in the proposed test provided a sensitivity of $94 \%$ and a specificity of $76 \%$.

Conclusion: The index we describe is aimed at predicting DI in a very specific population with a high risk of this complication. This index uses a series of variables which may be measured easily during the preoperative period and provides an excellent predictive capacity with a high sensitivity and specificity when the index is $\geq 5$.

Objectif : La prédiction de difficulté d'intubation orotrachéale (DI) chez des patients qui subissent une micro-intervention laryngée pourrait contribuer à réduire la morbidité et la mortalité associées à cette situation clinique. Nous avons étudié I I variables et leur association avec la DI chez ces patients afin d'établir une cotation simple pour prédire la difficulté.

Méthode : L'étude a intégré 181 patients. Les variables évaluées ont été : le grade de Mallampati, la distance thyromentonnière, l'ouverture de la bouche, le mouvement de l'articulation temporo-mandibulaire, la courbure du palais, le mouvement de la tête et du cou, la position fuyante de la mandibule, l'indice de masse corporelle et les symptômes cliniques d'affection laryngée et supraglottique. Pour établir la cotation, nous avons appliqué les coefficients de régression des variables significatives à l'analyse de régression logistique ajustée.

Résultats : La Dl était présente chez 50 patients (28\%) et l'intubation orotrachéale a été impossible chez quatre d'entre eux (2\%). Toutes les variables évaluées, saufl'obésité, ont permis de prédire la DI. Un test prédictif simple a été créé, fondé sur l'analyse de régression logistique incluant toutes les variables, sauf le mouvement de l'articulation temporo-mandibulaire. Nous avons appliqué une méthode d'analyse par les courbes $R O C$ afin de déterminer la limite optimale du nouveau test. Une valeur $\geq 5$ présentait une sensibilité de $94 \%$ et une spécificité de $76 \%$.

Conclusion : L'indice décrit vise à prédire la DI dans une population très spécifique de patients à haut risque de cette complication. Cet indice comprend une série de variables qui peuvent être mesurées facilement avant l'opération et il présente une excellente capacité de prédiction. II a une sensibilité et une spécificité élevées pour des valeurs $\geq 5$.

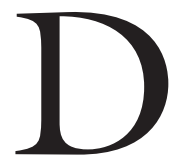
IFFICULTY in airway management is one of the aspects which concerns anesthesiologists most and which leads to the greatest repercussions in regard to anesthetic morbidity-mortality. There is a wide variety of presurgical tests for predicting difficult intubation (DI), ${ }^{1,2}$ however, the predictive tests applicable in the

From the Department of Anesthesiology, Hospital Clínic Universitari of Barcelona, Barcelona, Spain.

Address correspondence to: Dr. M.A. Ayuso, Servicio Anestesiología y Reanimación, Hospital Clinic Universitari, C/Villarroel 170,

08034 Barcelona, Spain. Phone: 34-932275558; E-mail: 6691ayc@comb.es

Accepted for revision June 3, 2002.

Revision accepted October 18, 2002

CAN J ANESTH $2003 / 50: 1 /$ pp 81-85 
TABLE I Definition of the risk factors for difficult intubation (DI) evaluated in this study

\begin{tabular}{|c|c|c|}
\hline Risk factor & Value 0 & Value 1 \\
\hline $\begin{array}{l}\text { Mallampati test modified by } \\
\text { Samsoon and Young }{ }^{1}\end{array}$ & Grade I and II & Grade III and IV \\
\hline Thyromental distance (TMD) ${ }^{6}$ & $\geq 6.5 \mathrm{~cm}$ & $<6.5 \mathrm{~cm}$ \\
\hline Mouth opening (MO) & $\geq 4 \mathrm{~cm}$ & $<4 \mathrm{~cm}$ \\
\hline $\begin{array}{l}\text { Temporomandibular joint } \\
\text { movement }(\mathrm{TMJM})^{2}\end{array}$ & $\begin{array}{l}\text { The patient is able to } \\
\text { move the lower incisors in } \\
\text { front of the upper incisors }\end{array}$ & $\begin{array}{l}\text { The lower incisors } \\
\text { remain behind or aligned } \\
\text { with the upper incisors }\end{array}$ \\
\hline Dentition & $\begin{array}{l}\text { Normal incisors or the total } \\
\text { absence of teeth }\end{array}$ & $\begin{array}{l}\text { Mobile or protruding } \\
\text { incisors }\end{array}$ \\
\hline Maxillary deficiency & None & $\begin{array}{l}\text { Presence of maxillary } \\
\text { hypoplasia and/or arched } \\
\text { palate }\end{array}$ \\
\hline Head and neck mobility $(\mathrm{NM})^{2}$ & $>90^{\circ}$ & $\leq 90^{\circ}$ \\
\hline $\begin{array}{l}\text { Receding mandible (lateral view } \\
\text { of the face })^{2}\end{array}$ & $\begin{array}{l}\text { Mandible not receding to } \\
\text { maxilar }\end{array}$ & Mandible receding to maxilar \\
\hline Body mass index (BMI) & $\leq 30$ & $>30$ \\
\hline $\begin{array}{l}\text { Clinical manifestations of } \\
\text { laryngeal dysfunction }\end{array}$ & Hoarseness alone & $\begin{array}{l}\text { Symptoms of laryngeal } \\
\text { insufficiency: stridor, inspiratory dyspnea, } \\
\text { dysphagia or impossible swallowing }\end{array}$ \\
\hline $\begin{array}{l}\text { Supraglottic localization of } \\
\text { laryngeal pathology } \\
\text { the base of the tongue }\end{array}$ & No supraglottic localization & $\begin{array}{l}\text { Exophytic process in the } \\
\text { supraglottic region or with involvement of }\end{array}$ \\
\hline
\end{tabular}

TABLE II Criteria for difficult intubation

\begin{tabular}{lllll}
\hline Cormack grade & $\begin{array}{l}\text { Difficulty in } \\
\text { anatomical } \\
\text { identification }\end{array}$ & $\begin{array}{l}\text { Use of auxillary } \\
\text { methods }\end{array}$ & $\begin{array}{l}\text { Difficult tracheal } \\
\text { intubation } \\
\text { (number of } \\
\text { patients) }\end{array}$ & $\begin{array}{l}\text { Impossible } \\
\text { tracheal } \\
\text { intubation } \\
\text { (number of } \\
\text { patients) }\end{array}$ \\
\hline Not identifiable & Yes & & 4 \\
II & - & Yes & 4 & 4 \\
III & - & - & 21 & 4 \\
& Yes & - & 9 & \\
IV & - & Yes & Yes & 12 \\
\hline
\end{tabular}

In eight patients $(4.4 \%)$ glottic identification was difficult (four) or impossible (four). In 25 patients (13.8\%) auxillary methods were used to achieve tracheal intubation. Intubation was not possibe in four patients $(2.2 \%)$.

general population are not adequate for use in patients with laryngeal disease ${ }^{3,4}$ in whom the incidence of DI is greater because of localization of the surgical site. ${ }^{5}$ Considering the relevance of detecting DI preoperatively in patients with laryngeal disease, we sought to determine a simple test to, preoperatively, identify patients who may present this difficulty.

\section{Methods}

One hundred eighty-one consecutive adult patients with laryngeal disease scheduled to undergo laryngeal microsurgery under general anesthesia with orotracheal intubation (OTI) were included in the study.
Patients with acute respiratory insufficiency with a baseline $\mathrm{SpO}_{2}<85 \%$ were excluded.

Preoperative evaluation was carried out by an anesthesiologist with experience in otorhinolaryngology (ENT) surgery. The variables evaluated are shown in Table I.

The management of anesthesia was carried out according to a pre-established protocol by an expert anesthesiologist blinded to the preoperative evaluation of the airway. Direct laryngoscopy was undertaken according to the Cormack and Lehane scale, ${ }^{7}$ in the sniffing position with spontaneous ventilation and prior to the administration of a muscle relaxant. The best possible glottic view was graded applying external 
TABLE III Statistical results of the prediction capacity of the different variables studied (univariate analysis, Chi- square test)

\begin{tabular}{|c|c|c|c|c|c|c|c|c|c|c|}
\hline Risk factor & $\begin{array}{l}\text { True } \\
+ \\
(n)\end{array}$ & $\begin{array}{l}\text { True } \\
- \\
\text { (n) }\end{array}$ & $\begin{array}{l}\text { False } \\
+ \\
(n)\end{array}$ & $\begin{array}{l}\text { False } \\
- \\
(n)\end{array}$ & $\begin{array}{l}\text { Sensitivity } \\
(\%)\end{array}$ & $\begin{array}{l}\text { Specificity } \\
(\%)\end{array}$ & $\begin{array}{l}P P V \\
(\%)\end{array}$ & $\begin{array}{l}\text { NPV } \\
(\%)\end{array}$ & $\begin{array}{l}\text { Odds ratio } \\
\text { (CI 95\%) }\end{array}$ & $\begin{array}{l}\text { Chi-square } \\
(P)\end{array}$ \\
\hline Mallampati III-IV & 29 & 101 & 26 & 25 & 54 & 80 & 53 & 80 & $4.5(2.3-9)$ & $<0.01$ \\
\hline $\begin{array}{l}\text { Thyromental distance } \\
<6.5 \mathrm{~cm}\end{array}$ & 16 & 120 & 7 & 38 & 30 & 94 & 70 & 76 & $7.2(2.8-19)$ & $<0.01$ \\
\hline Mouth opening $<4 \mathrm{~cm}$ & 32 & 99 & 28 & 22 & 59 & 78 & 53 & 82 & $5.1(2.6-10)$ & $<0.01$ \\
\hline Limitation TMJ & 8 & 123 & 4 & 46 & 15 & 97 & 67 & 73 & $5.3(2.1-19)$ & $<0.05$ \\
\hline Pathological dentition & 16 & 115 & 12 & 38 & 30 & 91 & 57 & 75 & $4(1.8-9)$ & $<0.01$ \\
\hline Maxillary deficiency & 9 & 124 & 3 & 45 & 17 & 98 & 75 & 73 & $8.3(2.1-32)$ & $<0.01$ \\
\hline Neck mobility $<90^{\circ}$ & 36 & 90 & 37 & 18 & 67 & 71 & 49 & 83 & $4.9(2.5-10)$ & $<0.01$ \\
\hline Receding mandible & 15 & 122 & 5 & 39 & 28 & 96 & 75 & 76 & $9.4(3.2-27)$ & $<0.01$ \\
\hline $\mathrm{BMI}>30$ & 9 & 113 & 14 & 45 & 17 & 89 & 39 & 72 & & NS \\
\hline $\begin{array}{l}\text { Symptoms laryngeal } \\
\text { dysfunction }\end{array}$ & 11 & 122 & 5 & 43 & 20 & 96 & 69 & 74 & $6.2(2.1-19)$ & $<0.01$ \\
\hline $\begin{array}{l}\text { Tumour supraglottic } \\
\text { region }\end{array}$ & 15 & 122 & 5 & 39 & 28 & 96 & 75 & 76 & $9.4(3.2-28)$ & $<0.01$ \\
\hline
\end{tabular}

Risk factors are defined in Table I. True $+=$ true positive; True- = true negative; False $+=$ false positive $;$ False- $=$ false negative; PPV = positive predictive value; NPV = negative predictive value; $n=$ number of patients; $\mathrm{BMI}=$ body mass index; TMJ $=$ temporomandibular joint.

laryngeal manipulation (OELM maneuver) or backward, upward, rightward laryngeal displacement (BURP maneuver) by a second anesthesiologist.

Intubation was considered difficult in the following cases: a) when intubation was not achieved, and b) when intubation was achieved but the glottic view during laryngoscopy was Cormack grades III or IV; or anatomical alterations impeded the identification of the laryngeal structures and the glottic lumen; or auxillary equipment was required to achieve OTI (rigid stylet, fibroscope intubation or transtracheal jet ventilation).

Statistical analysis was performed using the SPSS 10.0 statistical package for Windows. The different variables were analyzed independently to evaluate their statistical influence on DI by univariate tests (Chi-square). Sensitivity, specificity and odds ratio were determined for each of the independent variables with statistical significance. To evaluate the influence of the different variables studied in the prediction of difficult tracheal intubation an unsaturated logistic regression model was used. Regression coefficients (B) of the statistically significant variables included in the regression analysis were used, (adjusted for relative weight) to create a simple test capable of predicting DI preoperatively. To determine the optimum cut off point of this simple test, a receiver operating characteristic (ROC) curve analysis was performed.

\section{Results}

One hundred eighty-one patients [134 males and 47 females; mean age $53.5 \pm 19.2 \mathrm{yr}$; body mass index (BMI): $27 \pm 4.2 \mathrm{~kg} \cdot \mathrm{m}^{2}$ ] were included in the study.
The grades of laryngoscopic view obtained according to the Cormack and Lehane scale were I in 84 patients $(46.4 \%)$, II in $47(26 \%)$, III in 34 (18.7\%), and IV in $12(6.6 \%)$. In four $(2.2 \%)$ cases the glottic space was not recognized due to a large tumoral deformation of all the larynx.

The incidence of DI according to the predefined criteria was $30 \%$ ( 54 patients), intubation was impossible in four ( $2.2 \%$ of the patients) and tracheostomy was carried out. Intubation was possible in the remaining 50 patients $(28 \%)$. Table II details the cases of DI.

Forty-eight patients (26.5\%) had a supraglottic (39 patients) or glottic (nine patients) neoplastic process, while in 133 patients the disease was non-neoplastic. DI was encountered in 60\% (24 patients) of neoplastic patients and in 22\% (29 patients) of non-neoplastic patients $(P<0.05)$.

On univariant statistical analysis all the variables, except BMI, showed DI to be statistically significant $(P<0.05)$. However, individually, these variables showed low predictive reliability as demonstrated by the values of sensitivity, specificity and positive and negative predictive value (Table III).

On logistic regression analysis it was found that all the variables, except for mobility of the temporomandibular joint and grade II Mallampati, were independent and predicted DI in this group of patients (Table IV). A simplified risk score was calculated by adding the adjusted $\mathrm{B}$ values obtained (Table IV). On analysis of the ROC curve with the simple score, the optimum cut-off was 5 (a score $\geq \mathbf{5}$ provides a sensitivity of $94 \%$ and a specificity of $76 \%$ ). With a cut-off of $\geq$ 
TABLE IV Independent factors related to difficult orotracheal intubation

\begin{tabular}{llll}
\hline Risk factor & $P$ & $\begin{array}{l}B \\
\text { (B values from } \\
\text { regression analysis) }\end{array}$ & $\begin{array}{l}\text { Adjusted value } \\
\text { (values used to } \\
\text { calculate risk score) }\end{array}$ \\
\hline Mallampati II & & - & - \\
Mallampati III & 0.104 & 3.14 & 3 \\
Mallampati IV & 0.006 & 4.35 & 4 \\
Thyromental distance $<6.5 \mathrm{~cm}$ & 0.026 & 2.34 & 2 \\
Mouth opening < $40 \mathrm{~mm}$ & 0.039 & 2.42 & 2 \\
Limitation of temporomandibular joint & 0.003 & - & - \\
Pathological dentition & 0.762 & 2.92 & 3 \\
Maxillary deficiency & 0.000 & 4.61 & 5 \\
Neck mobility $\leq 90^{\circ}$ & 0.002 & 2.25 & 2 \\
Receding mandible & 0.002 & 3.41 & 3 \\
Symptoms of laryngeal dysfunction & 0.003 & 3.63 & 4 \\
Tumour of supraglottic region & 0.001 & 5.22 & 5 \\
\hline
\end{tabular}

4 the sensitivity was $100 \%$ and the specificity was $64 \%$; being $89 \%$ and $89 \%$, respectively with a cut-off of $\geq 6$.

\section{Discussion}

There is an elevated incidence of DI in patients with laryngeal disease and we developed a preoperative test that provides an excellent predictive capacity with a sensitivity of $94 \%$ and a specificity of $76 \%$ when the index result is $\geq 5$.

The elevated incidence of DI observed may be largely explained by all aspects of laryngeal disease (airway tumour, dental pathology, previous radiotherapy, etc...). In the general population the incidence of DI ranges from $0.5-2 \%,{ }^{8}$ and in ENT surgery DI ranges from $8-10 \%{ }^{4}$ Nonetheless, the incidence of DI rises to $28 \%{ }^{4}$ when the patient presents a tumour of the airway, as was the case in our study.

Different factors determine the incidence of DI including the criteria adopted to define DI. ${ }^{8}$ According to the criteria of Tse $^{9}$ and Pottecher, ${ }^{8}$ we considered that a Cormack grade 3 laryngoscopy may be associated with technical difficulties in tracheal intubation. On the other hand, other factors such as a severe stenosis of the glottic lumen impeding the introduction of the endotracheal tube and a large supraglottic tumour making localization of the position of the glottis or recognition of the laryngeal anatomical structures difficult, have been considered criteria for DI. ${ }^{4}$ We took numerous criteria into account to improve the prediction of DI in an attempt to decrease the morbidity associated with anesthesia in patients with pharyngo-laryngeal disease.

Predictive tests applicable to the general population are not adequate for use in patients with laryngeal disease. The Mallampati test applied in the general pop- ulation presents a sensitivity of $84 \%$ but its subjectivity has been criticized ${ }^{10}$ as has its low sensitivity in specific groups. Thus, in ENT surgery, the sensitivity of this test decreases to $60 \%$ having a specificity of $72 \%{ }^{3}$ Application of the Wilson index to a general population has a sensitivity of $75 \%$ with a specificity of $88 \%{ }^{2}$ Nonetheless, when it is applied to patients with an airway tumour, the sensitivity decreases to $9 \%$, with a specificity of $93 \% .{ }^{4}$ Therefore, the specific aspects of pharyngo-laryngeal disease should be considered when developing a test applicable for the screening of DI in the preoperative period. The simple test we propose demonstrates a sensitivity of $94 \%$ and a specificity of $76 \%$ when score results $\geq 5$. This is probably due to the inclusion of an important factor such as the supraglottic localization of the lesion which may present great difficulties in localization of the glottis since our objective was exclusively for laryngeal disease and not for other ENT surgical pathologies.

The statistical methodology applied in the study by Arné et al. ${ }^{5}$ was similar to that developed in our study and was based on logistic regression analysis of the different variables predicting DI. This statistical analysis requires a high number of cases to be reliable. The high incidence of DI and the application in such a specific population makes the results of the statistical analysis more reliable and reproducible. However, contrary to the study by Arné et al. ${ }^{5}$ we did not include a validation group of patients.

In conclusion, we developed a simple index aimed at predicting DI in a very specific population of patients undergoing laryngeal microsurgery with a high risk of DI. This index uses a series of variables which may be measured easily during the preoperative period and provides an excellent predictive capacity with a high sensi- 
tivity and specificity when the index result is $\geq 5$.

However, a validation study remains necessary.

\section{References}

1 Samsoon GLT, Young JRB. Difficult tracheal intubation: a retrospective study. Anaesthesia 1987; 42: 487-90.

2 Wilson ME, Spiegelhalter D, Robertson JA, Lesser P. Predicting difficult intubation. Br J Anaesth 1988; 61: 211-6.

3 Bergler W, Maleck W, Baker-Schreyer A, Ungemach J, Petroianu G, Hormann $K$. The Mallampati score. Prediction of difficult intubation in otolaryngologic laser surgery by Mallampati score (German). Anaesthesist 1997; 46: 437-40.

4 Descoins P, Arné J, Bresard D, Ariès J, Fusciardi J. Proposal of a new multifactorial score to predict difficult intubation in ENT and stomatological surgery. A preliminary study (French). Ann Fr Anesth Réanim 1994; 13: 195-200.

5 Arné J, Descoins P, Fusciardi J, et al. Preoperative assessment for difficult intubation in general and ENT surgery: predictive value of a clinical multivariate risk index. Br J Anaesth 1998; 80: 140-6.

6 Frerk CM. Predicting difficult intubation. Anaesthesia 1991; 46: 1005-8.

7 Cormack RS, Lehane J. Difficult tracheal intubation in obstetrics. Anaesthesia 1984; 39: 1105-11.

8 Pottecher TH, Velten M, Galani M, Forrler M. Compared predictive value of clinical signs of difficult intubation in women (French). Ann Fr Anesth Reanim 1991; 10: 430-5.

9 Tse JC, Rimm EB, Hussain A. Predicting difficult endotracheal intubation in surgical patients scheduled for general anesthesia: a prospective blind study. Anesth Analg 1995; 81: 254-8.

10 Charters P, Perera S, Horton WA. Visibility of pharyngeal structrures as a predictor of difficult intubation (Letter). Anaesthesia 1987; 42: 1115. 